\title{
Review Article of Radio Frequency and Microwave Heating Treatment to Disinfest Kutu Beras in Malaysian Rice
}

\author{
Siti Zulaika Abdul Nyzam ${ }^{l,}$ Rosemizi Abd. Rahim ${ }^{1, *}$, and Hasliza A. Rahim @ Samsuddin ${ }^{1}$ \\ ${ }^{1}$ Biolectromagnetic Research Group (BioEM), School of Computer and Communication Engineering, Universiti Malaysia Perlis, Arau, \\ Perlis, Malaysia.
}

\begin{abstract}
This article presents the basic principle of radio frequency (RF) and microwave heating and its application in agricultural sector specifically to control rice insects for storage purpose. Experiment findings of the past few years are highlighted according to the heating mechanism which influence the response of rice and insect exposed to the microwave field.
\end{abstract}

\section{Introduction}

Microwave heating has been considered to be one of the methods to control stored grain insects since early $20 \mathrm{~s}[1]$. The production of rice in Malaysia is seasonal. It is important to ensure the storage of stock meet the continuous demand and avoid the problem of shortage of supply. According to a study conducted by two partners of Malaysia in rice industry, Malaysian Agricultural Research and Development Institute (MARDI) and Bernas, near $50 \%$ of the rice storage is damage caused by the insect i.e. rice weevils, also known as bubuk or kutu beras in Malaysia. It is one of the most serious stored grain pests and originated in India but has been spread worldwide by trade[2]. The current insects controlling methods involve the use of physical, biological and chemical methods but they come with several disadvantages such as it takes time to present the results, low precision in ability to control disinfestation of large volume of grain, consequently much damage occur before the treatment is working and drawback of insecticide pests used in chemical method has grows attention in developing treatment method by using radio frequency (RF) and microwave heating method. This method has never been practically used in the industry and this paper will highlight the trial of experimenting this method in order to bring it into the industry for commercial purpose especially in controlling rice infestation.

\section{Methods of Controlling Rice Insects}

The process of paddy rice has to go through a lot of stages before it is marketed to the consumers. Inevitably, the major loss of paddy rice during the processes has been estimated caused by the rice weevils. This insects also act as the transportation of storage fungi which encouraging the infestation in rice[3]. Current insects controlling methods involve the use of physical, biological, chemical methods and a few developing technology in electrical methods. However, these methods have several disadvantages and some safety concern due to their effects on the rice nutrition and consumers.

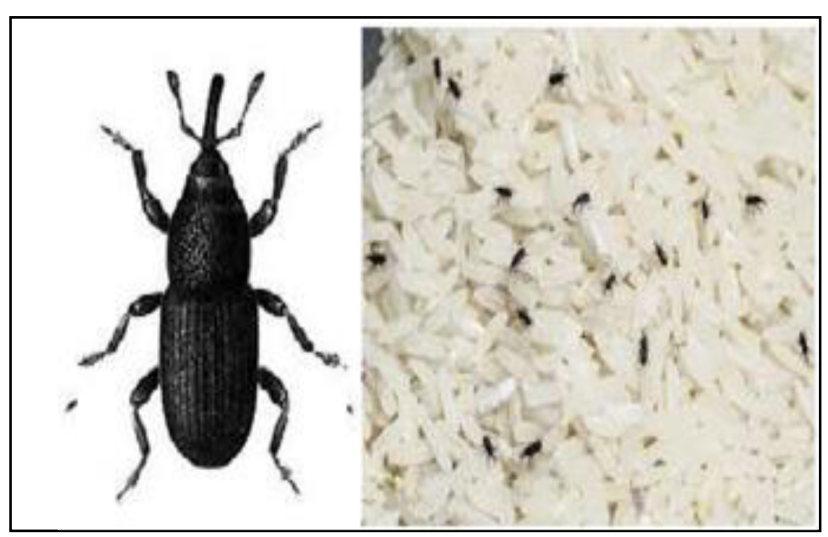

Fig. 1. Rice Weevil

\subsection{Physical Method}

The physical methods were the main methods in controlling stored grain before the use of chemical substances. It involves the manipulation of the physical environment or applying physical treatment to the rice such as manipulation of the physical environment, mechanical impact, physical removal, abrasive and inert dusts[4].

\footnotetext{
* Corresponding author: rosemizi@unimap.edu.my
} 
In manipulating the physical environment, the temperature control is usually used to slow down degradation of produce caused by the insects. Both low and high temperature can be effective depending on rate of temperature change and the period of exposure. Next, the use of inert dusts are effective due to their low mammalian toxicity[4]. They slowly effect several mechanism that lead to dehydration especially absorption of cuticular lipid and abrasion. In mechanical aspect, polishing techniques is used by rubbing off the pericarp of rice grains[4]. Result experiment conducted by Luca et al shows that polishing to a weight loss of $11 \%$ of rice grains causes $40 \%$ severe mortality in rice weevil, Sitophilus Oryzae, eggs, followed by another $40 \%$ mortality remaining to the poor suitability of polished rice grains[5].

Nevertheless, physical control method could take a long time to show a satisfied result and it needs highly precise actions to control insects within a large volume of grain.

\subsection{Biological Method}

Biological control is a purposeful manipulation of population to living useful organisms to control the population of pests[6]. This useful organisms are called as natural enemies which attack the stored grain insects. The three major classes of natural enemies are predators, parasite and pathogens[7]. The major advantage of biological enemies that the natural enemies only need to be release at only one location[8]. They will keep reproducing their species and spread through the wide area of stored grain.

Specific species of natural enemies are needed to kill each of the insect pests. These natural enemies are released in the stored grain and they will attack the insects. This method is considered safe to the consumer and environment as there is no chemical substance involved.

The disadvantage of this method is a lot of precise information and perfect timing are needed to release the natural enemies. The release has to be early enough before the insect pests outnumber them[8]. Most of the natural enemies are specific host, which make it necessary to ensure the right pests species that causing the problem[8]. Also, this method is considered slow in action and taking risk of consequently damage may occur before the treatment is effective.

\subsection{Chemical Method}

Chemical methods are used widely due to low cost, the essential for the efficient production, preservation of food product and ease of use. Two classes of the chemical used to control the insects in the bulk stored grains are contact insecticide and fumigants.

The contact insecticide is sprayed directly to the rice grains and kill the insects when they contact with the treated surface. The popular insecticides are malathion, chlorypyrifosmethyl and pirimiphosmethyl. However, some of the insect have become immune to these chemicals substances due to wide spread resistance in insects population[3]. A survey of stored product insects shows $87 \%$ of 505 strain of the red flour beetle, Trobolium castaneum, from 78 countries were resistant to malathion and resistance to phosphine is great in Australia and India[9].

Fumigants are gaseous insecticides types applied to control the insects in the grains. It is a better chemical method as it can reach the inaccessible area by the contact insecticides type. The fumigants gaseous are methyl bromide $(\mathrm{MeBr})$ and phosphine. However, it has been found that methyl bromide is a risk to the Earth's ozone layer[10]. It also creates damage to the environment and dangerous for human's health as it may still remain in the rice even though the gaseous is applied limitedly. Also, the fumigants is proven to kill larvae and mature insects but it does not guaranteed to successfully disinfect the survived eggs inside the kernels[11]. Therefore, the interest in discovering covering the alternative method with chemical-free has drawn the attention to the application of electromagnetic wave to control stored grain insects.

\subsection{Electrical Methods}

Conventional heating is considered as an electrical method. Heat disinfestation is an alternative way to replace chemical method. In conventional heating, heat is diffused from the surface into the interior of the material by convection or conduction in the particles. Many application of conventional heating use hot air or hot water to control the insect infestation by increasing the temperature. The advantages of this method are that the process is easy to conduct, no chemical involve and it leaves no residue. It was reported that ideal temperature to kill all stages of insects is between $25^{\circ} \mathrm{C}$ to $35^{\circ} \mathrm{C}[3]$. However, this method take a huge amount of treatment time because of the slow rate of heat transfer within the material. It took $23 \mathrm{~min}$ and 6 hours for the centre of the fruit to reach the desired maximum temperature for cherries and apple respectively[12], [13]. This disadvantage lead to another cause which is the alteration of flavour compound.

Dielectric heating and microwave heating also have been considered to replace most of the current methods in controlling stored grain insect. Dielectric heating is also known as RF heating. Both RF and microwave heating have the same concept but each of them use different electromagnetic spectrums. Microwave heating commonly use frequency of $915 \mathrm{MHz}$ and $2450 \mathrm{MHz}$ while RF use 13, 27 and $40 \mathrm{MHz}$. In RF, the most famous design used in conducting the heating is two parallel plates electrodes with the material in between them. The power dissipated in the material can be expressed as,

$$
\mathrm{P}=\mathrm{E}^{2} \sigma=55.63 \times 10^{-12} \mathrm{fE}^{2} \varepsilon^{\prime \prime}
$$

where: $\mathrm{P}=$ the power dissipated,

$\mathrm{f}=$ the frequency used,

$\mathrm{E}=$ the rms electric field intensity 
$\varepsilon "=$ the dielectric loss factor.

\section{General Principles}

The permittivity of a material is a complex quantity consists of real part and imaginary part. Relative to free space, permittivity can be expressed as $\varepsilon^{*}=\varepsilon^{\prime}-j \varepsilon^{\prime \prime}$. The real part, $\varepsilon$, is called as the dielectric constant representing the capability in storing the energy in the electric field in the material. The imaginary part, $\varepsilon$, , is called as dielectric loss factor representing the dissipation of electric energy in the material which transform the electric energy to heat.

Microwave heating is the use of the electromagnetic waves and it involves heat transfer to beam up the material exposed to its radiation. Its frequency range is from $300 \mathrm{MHz}$ to $300 \mathrm{GHz}$ and it lies between radio frequencies and infrared radiation[14]. The rapidly varying electric and magnetic fields lead to the occurrence of heating. Electric field induced by the microwave field will cause dipolar molecules such as water and fat to oscillate back and forth and lead to heat dissipation in the material exposed[15]. The conversion of microwave energy to heat can be expressed as,

$$
\mathrm{P}=2 \pi \mathrm{E}^{2} \mathrm{f} \varepsilon \varepsilon_{\mathrm{o}} \mathrm{V}
$$

where: $\mathrm{P}=$ power

$\mathrm{E}=$ the electric field intensity

$\mathrm{f}=$ frequency

$\varepsilon "=$ dielectric loss factor

$\varepsilon_{o}=$ the permittivity of free space

$\mathrm{V}=$ volume of the material.

By comparing the penetration depth between RF and microwave heating, RF allow the deeper depth than in microwave heating according to the relationship of the frequency and the wavelength. Also, the two parallel plate electrodes design in RF can achieve a uniform field intensity is the material is homogeneous[1].

The major advantage of microwave heating is it heats the material volumetrically where material under the field directly absorb microwave energy and transform it to heat. Unlike the conventional heating, by using microwave energy, the heat is absorbed directly and internally by the material. Hence, microwave heating is considered efficient and reliable in overcoming not only the problem of long time treatment but also in getting rid of the insects both inside and outside the kernels.

\section{Experimental Findings}

This paper discusses several experiments related to RF and microwave heating treatment. The important element of this method is the measurement of dielectric properties of the targeted commodities and the specific host insects to determine the how the two subjects respond towards the electromagnetic wave. Dielectric properties of a material is influenced by temperature, frequency and moisture content[16]. Hence, it needs to be measured as a function of temperature and also important to choose the optimal frequency[17]. An attempt to measure data values of permittivity of adult Sitophilus Oryzae has been done by Stuart Nelson et al at 1997 at wide frequency of $0.2 \mathrm{GHz}$ to $20 \mathrm{GHz}[18]$. The measurement was taken at four different temperature which were $25,40,50$ and $60^{\circ} \mathrm{C}$ with the bulk density of $0.613 \mathrm{~g} / \mathrm{cm}^{3}$. Due to the nearness between the size of the insect and the end of the coaxial probe, the variability in the taken measurement may be caused by the differences of the effective density of the sample and the mean sample bulk density calculated. It was resolved that the dielectric loss factor of insects does not show good respond as presented for dielectric heating of the insects at range frequencies up to 20 $\mathrm{GHz}[18]$. It increased as the temperature rose and appear significant at temperature higher than $50^{\circ} \mathrm{C}$.

Manjur et al in 2011, carried out the measurement of permittivitties values of Rhd and Malaysian paddy MR219. The data recorded the higher values of permittivities for insects compared to the paddy. The reading of permittivities for paddy was basically independent of frequency while for Rhd, $\varepsilon$ ' degrade as the frequency rise and $\varepsilon$ " increased and remain constant from $7.5 \mathrm{GHz}$ to $20 \mathrm{GHz}[17]$. The result of permittivities of $\varepsilon$ " in the function temperature at $23-65^{\circ} \mathrm{C}$ under specific frequency showed close interaction between $2.45 \mathrm{GHz}$ up to $5 \mathrm{GHz}$ as shown in Figure 2. Therefore, it concluded as the operating frequency of $2.45 \mathrm{GHz}$ for industrial microwave has important influence to reach complete mortality of Rhd.

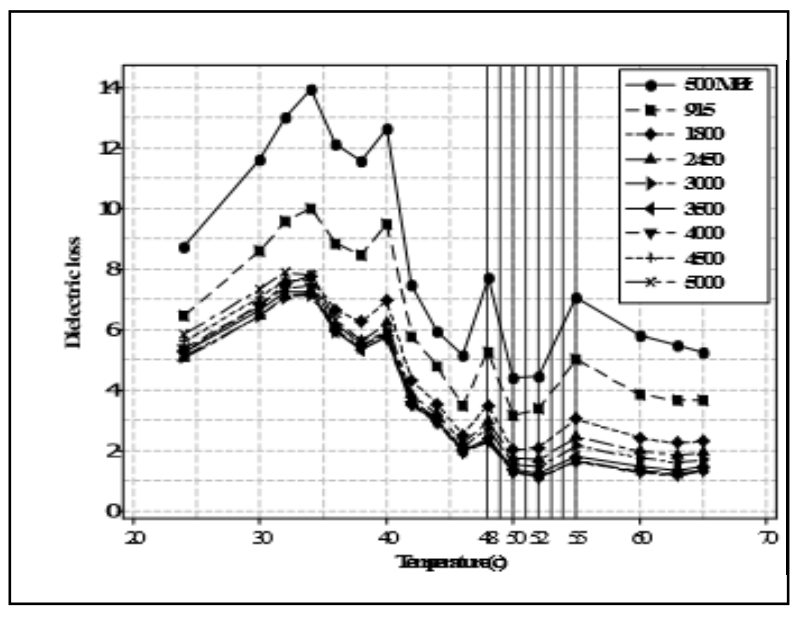

Fig. 2. Dielectric loss factor of Rhyzopertha Dominica (Rhd) in a function of temperature at specific frequencies

A new model was developed to directly obtain the values of $\varepsilon$ ' and $\varepsilon$ " of Rhd under the frequency and temperature as described in equation 3 and 4[17],

$$
\begin{aligned}
\varepsilon^{\prime}= & 52.272-1.407 \times 1.159 \times \mathrm{T}+0.017 \\
\times & \mathrm{F}^{2}+0.006 \times \mathrm{T}^{2}+0.017 \times \mathrm{F} \times \mathrm{T} \\
\varepsilon^{\prime \prime}= & 19.1867-0.100 \times \mathrm{F}-0.446 \times \mathrm{T}+ \\
& 0.012 \times \mathrm{F}^{2}+0.03 \times \mathrm{T}^{2}+0.005 \times \mathrm{F} \times \mathrm{T}
\end{aligned}
$$

where $\mathrm{F}=$ frequency from $200 \mathrm{MHz}$ to $20 \mathrm{GHz}$ $\mathrm{T}=$ temperature from 23 to $66^{\circ} \mathrm{C}$. 
Two famous insect pests often found in rice are Sitophilus Oryzae and Rhyzopertha Dominica (Rhd). Insect at adult stage is exposed the most under the electromagnetic field rather than insects at the immature stage and young adult are found more resistant to the treatment compared to the older ones[16]. Robert in 1974 recorded, the mature larva or pupae are more resistant to the microwave treatment compared to the immature larva or eggs[19]. Jose Franco in 2013, insects in at immature stages which are larva and pupae inside the rice are easier to be killed as the treatment time needed was only 100 seconds to achieve $100 \%$ mortaility while the egg stage needed a longer exposure which was 130 seconds[20]. The study of RF treatment in $2005,100 \%$ mortality was reported in 25 adult Rhd inside and outside of the rice seed under the RF treatment at $27.12 \mathrm{MHz}$ with temperature range from $70^{\circ} \mathrm{C}$ to $85^{\circ} \mathrm{C}$ for 180 seconds by Pattaya Janhang et al. $70^{\circ} \mathrm{C}$ was suggested to be the minimum temperature which provide complete mortality and maintain the seed viability at its maximum level at the same time[21]. With the same use of frequency, Wornwimol Wangspa led several experiments to determine the most tolerant stage of Sitophilus Oryzae and studied the number of progeny of this species after the treatment process. Under condition of $50^{\circ} \mathrm{C}$ for 180 seconds, it was found that eggs stage suffered complete mortality while the mortality of larva, pupa and adults are $79.1 \pm 5.1$, $80.9 \pm 7.3$ and $96.5 \pm 2.3 \%$ respectively[22]. It was shown the treatment sufficiently kill the insects compared to the untreated rice where the mortality of eggs, larva, purva and adult were $6.50 \pm 1.5 \mathrm{~d}, 9.25 \pm 1.5 \mathrm{~d}, 7.00 \pm 1.4 \mathrm{~d}$ and $6.50 \pm 0.6 \mathrm{~d}$ respectively. The survivor insects were used after 6 weeks of storage in succeeding experiment to observe the hatching eggs and reproduction capability and the number of progeny was proven to be less compared to the controlled rice sample. In another experiment, adult rice weevil was used to find the combination of temperature and time was experimented with temperature range of 50 to $70^{\circ} \mathrm{C}$ for 90 to 180 seconds and the result is as shown in Figure 3[22].

\begin{tabular}{|c|c|c|c|c|c|}
\hline \multirow{2}{*}{$\begin{array}{c}\text { Time } \\
(\mathrm{sec})\end{array}$} & \multicolumn{5}{|c|}{ Mortality of rice weevil $(\%) \pm \mathrm{SE}$ at various temperature } \\
\cline { 2 - 6 } & 50 & 55 & 60 & 65 & 70 \\
\hline $\begin{array}{c}\text { Untreated } \\
\text { sample }\end{array}$ & $9.25 \pm 0.9 \mathrm{~d}$ & $4.25 \pm 1.2 \mathrm{~d}$ & $2.50 \pm 0.6 \mathrm{~d}$ & $3.00 \pm 1.1 \mathrm{~d}$ & $5.00 \pm 0.7 \mathrm{~d}$ \\
\hline 90 & $58.22 \pm 1.9 \mathrm{c}$ & $93.03 \pm 2.9 \mathrm{a}$ & $99.11 \pm 0.8 \mathrm{a}$ & $99.17 \pm 0.8 \mathrm{a}$ & $99.04 \pm 0.9 \mathrm{a}$ \\
\hline 120 & $67.00 \pm 14.7 \mathrm{~b}$ & $98.08 \pm 1.9 \mathrm{a}$ & $99.08 \pm 0.9 \mathrm{a}$ & $100.00 \mathrm{a}$ & $100.00 \mathrm{a}$ \\
\hline 150 & $69.72 \pm 7.1 \mathrm{~b}$ & $99.14 \pm 0.8 \mathrm{a}$ & $100.00 \mathrm{a}$ & $100.00 \mathrm{a}$ & $100.00 \mathrm{a}$ \\
\hline 180 & $91.2 \pm 2.6 \mathrm{a}$ & $100.00 \mathrm{a}$ & $100.00 \mathrm{a}$ & $100.00 \mathrm{a}$ & $100.00 \mathrm{a}$ \\
\hline
\end{tabular}

Fig. 3. Average mortality of adult rice weevil for temperature range of 50 to $70^{\circ} \mathrm{C}$ for 90 to 180 seconds.
Microwave heating treatment was applied by Siming Zhao et al with Sitophilus Oryzae was subjected to the operating frequency of $2.45 \mathrm{GHz}$ in 2006 . The result obtained showed the adults was killed at $55^{\circ} \mathrm{C}$ and the eggs was killed at $54^{\circ} \mathrm{C}[23]$. A lethal model was developed to investigate the precise temperature at which it kills the insects from eggs and adults stage(thermal death kinetic) and can be described as in equation 5[23],

$$
\left\{\begin{array}{lr}
M=1-A\left(\frac{T_{1}-T_{0}}{T-T_{0}}\right)^{m}, & \left(T \geq T_{1}\right) \\
M=e, & \left(T_{0}<T<T_{1}\right) \\
M=0, & \left(T \leq T_{0}\right)
\end{array}\right.
$$

where: $T_{1}=$ initial temperature of rice,

$T_{0}=$ the final temperature recorded when complete mortality is reached

$\mathrm{A}=$ the susceptibility factor which indicate how easy the easy are killed. $\mathrm{m}=$ coefficient fitted to the model

Manjur et al conducted similar exploration with insect species of Rhd. It recorded mortality for time treatment from 40 to 60 seconds and the complete mortality was reached at the maximum treatment time[17]. With condition of $78^{\circ} \mathrm{C}$ for 60 seconds treatment, $300 \mathrm{gm}$ of Rhd was studied on three different holding time to observe the mortality rate and the effect of holding time. The result as in tabulated in Table 1. The effect of holding time is need significant consideration in designing the treatment to reach lethal temperature in order to obtain high mortality rate[24].

Table 1. Holding time effect on mortality rate of Rhd under microwave power of $1 \mathrm{~kW}$.

\begin{tabular}{|c|c|c|}
\hline $\begin{array}{c}\text { Temperature } \\
\text { and time }\end{array}$ & $\begin{array}{c}\text { Holding Time } \\
(\mathbf{m i n})\end{array}$ & $\begin{array}{c}\text { Mortality } \\
(\mathbf{\%})\end{array}$ \\
\hline \multirow{3}{*}{$\begin{array}{c}78^{\circ} \mathrm{C} / 60 \\
\text { seconds }\end{array}$} & 3 & 98.4 \\
\cline { 2 - 3 } & 10 & 99.2 \\
\hline
\end{tabular}

In term of heating rate and energy, it can be concluded that higher heating rate provide low mortality and it needs longer holding time to reach high mortality as low heating rate can provide[24]. Siming Zhao reported complete disinfestation above energy consumption of 0.017 and $0.016 \mathrm{kWh} / \mathrm{ks}$ for adults and eggs respectively as the rice temperature from 55 to $62^{\circ} \mathrm{C}[23]$. Wormwimol Wangspa recorded $0.391 \mathrm{kWh}$ under treatment of $65^{\circ} \mathrm{C}$ for 120 seconds and $0.670 \mathrm{kWh}$ at $70^{\circ} \mathrm{C}$ for 180 seconds[22]. Both of the treatment caused $100 \%$ mortality. The energy consumption required to reach $100 \%$ mortality of adults is higher compared to eggs stage. Hence, eggs stage is easier to be killed and support the result obtained by Siming Zhao. 
Halverson in 1999 has investigated the lethal temperature for rice insects in wheat by using extremely high frequency (EHF) and super high frequency (SHF) and found that eggs were more thermo tolerant compared to other insect stages[25]. However, the penetration depth of the electromagnetic waves should be considered as it decreases as the frequency increases.

In 1974, Rai et al claimed that heat can reduce the quality of sperm cells and ovarian tissue of insects[1]. Consequently, Pattaya Janhang tested the rice viability by doing tetrazolium test to observe the rice viability and the results showed the viability was decreased to 90,82 , 64 and $39 \%$ as the temperature rose from $70,75,80$ and $85^{\circ} \mathrm{C}$ respectively[21]. Seed germination was affectedly drop to $89,86,57$ and $27 \%$ correspondingly to the rising temperature. Microwave specification for disinfestation purpose with high power, long time treatment and high energy consumption can provide high mortality rate of insects but it induces the rice to heat excessively. Siming Zhao suggested that $50^{\circ} \mathrm{C}$ as the minimum treatment temperature under controlled microwave power, treatment time and energy utilization to kill the insects and maintain the rice quality as high as possible[23].

\section{Conclusion}

This paper discusses several research and experiments related to the use of RF and microwave heating treatment to disinfest rice weevil for long time storage in the industry. The current methods used to overcome insect pest are physical, biological and chemical methods. However these methods result a few disadvantages as they take a long time to get rid of the insects, the needing of precise information of time and specific host insect to be killed and chemical methods is proven cannot reach the eggs stage inside the kernel and dangerous to the consumers and our environment. By using the electromagnetic wave energy, it can reduce the treatment time, ensure the complete mortality inside and outside the kernel and free chemical residue.

From the findings, it tells the importance of accurate data permittivities of the insects and commodities in order to investigate the suitable operating frequency, temperature and time treatment. Also, the data can help to develop the specification and design of application based on radio frequency and microwave heating. The permittivities values indicate the interaction between the rice and insect towards the radiation. High values of dielectric constant show strong interaction.

It also can be shown in most of the experiments above that the higher temperature caused higher mortality both in RF and microwave heating treatment. Pattaya Janhang recorded $70^{\circ} \mathrm{C}$ in the minimum temperature that caused completed mortality for 180 seconds in treating Rhyzopertha Dominica (Rhd) in rice seeds. Siming Zhao suggested $55^{\circ} \mathrm{C}$ to reach the complete mortality and maintain the maximum rice quality as well. Manjur reported in his experiment that $100 \%$ mortality of Rhd at 60 seconds with $1 \mathrm{~kW}$ power. The most tolerant stage of insect was mostly found in eggs both in RF and microwave treatment. This suggests that the effect of temperature on pest is high.

Las but not least, unavoidably, this method causes damage to the rice and under condition of extremely high temperature and time can lead the rice to heat excessively. Therefore, it is importance to precisely determine the combination of temperature, time and power at the minimum level to maintain the quality of the rice and healthy to the consumers.

\section{Acknowledgement}

The authors highly appreciate the support and would like to thanks Ministry of High Education (MoHE) for the financial funding under Fundamental Research Grant Scheme (FRGS 2016, 9003-00597).

\section{References}

1. S. O. Nelson, Trans. Am. Soc. Agric. Eng., 39 1475-1484, (1996)

2. P. G. Koehler, Univ. Florida IFAS Extension., 2-3, (2008)

3. I. Das, G. Kumar, N. G. Shah, Int. J. Food Sci., 2013 1-114, 2013.

4. F. F.-L. Vincent Charles, Guy Hallman, Bernand Panneton, Management of Agricultural Insects With Physical Control Methods (Annual Review of Neuroscience, Quebec, Canada, 2003)

5. É. Lucas, J. Riudavets, Stored-Product Quar. Entomol., 93 1837-1841, (2000)

6. D. Mahr, P. Whitaker, N. Ridgway, Biological control of insects and mites: an introduction to beneficial natural enemies and their use in pest management (Universiti of Wisconsin, Wisconsin, 2008)

7. M. a Altieri, C. I. Nicholls, M. a Fritz, Manage Insects on Your Farm: A Guide to Ecological Strategie (Sustainable Agriculture Research and Education(SARE), Maryland, 2005)

8. P. W. Flinn, M. Schöller, Stored Prod. Prot., 1-10, (1996)

9. R. Vadivambal, Can. Soc. Eng. Agric. Food Biol. Syst., 1-11, (2005)

10. J. G. Leesch, G. F. Knapp, B. E. Mackey, Stored Prod. Res., 36 65-74, (2000)

11. S. J. Langlinais, ASAE Tech. Pap., 46 16, (1989)

12. S. Wang, J. Tang, R. P. Cavalieri, Postharvest Biol. Technol., 22 257-270, (2001)

13. S. Wang, J. Tang, R. P. Cavalieri, Postharvest Biol. Technol., 22 29-38, (2001)

14. S. Jones, "Comparing Microwave to Conventional Heating and Drying Systems Mechanics Advantages Economics."

15. Y. Kueon, Int. Conf. Control. Autom. Syst. ICCAS 2008, 1966-1971, (2008)

16. S. O. Nelson, "Frequency dependence of the dielectric properties of wheat and the rice weevil," Iowa State University, 1972.

17. M. Ahmed, F. Malek, R. B. Ahmad, M. Rahman, K. 
M. Juni, World Acad Sci Eng Technol, 81 1-6, (2011)

18. S. O. Nelson, P. G. Bartley, K. C. Lawrence, IEEE Trans. Instrum. Meas., 46 941-946, (1997)

19. R. L. Kirkpatrick, Proc. Int. Work. Conf. Stored Prod. Entomol., 431-437, (1974)

20. J. G. Franco, S. S. H. Franco, C. H. Franco, P. B. Arthur, V. Arthur, Ina. 2013 Int. Nucl. Atl. Conf., 1-23, (2013)

21. P. Krutmuang, S. Mekchay, Conf. Int. Agric. Res. Dev. Stuttgart-Hohenheim, 1-8, (2005)

22. W. Wangspa, Y. Chanbang, S. Vearasilp, Chiang Mai Univ. J. Nat. Sci., 14 189-197, (2015)

23. S. Zhao, C. Qiu, S. Xiong, X. Cheng, J. Stored Prod. Res., 43 430-434, (2007)

24. S. Wang, J. N. Ikediala, J. Tang, J. D. Hansen, J. Stored Prod. Res., 38 441-453, (2002)

25. S. L. Halverson, T. W. Phillips, T. S. Bigelow, G. N. Mbata, Mark E. Payton, Atmos. Environ., 30 3001-3009, (1996) 